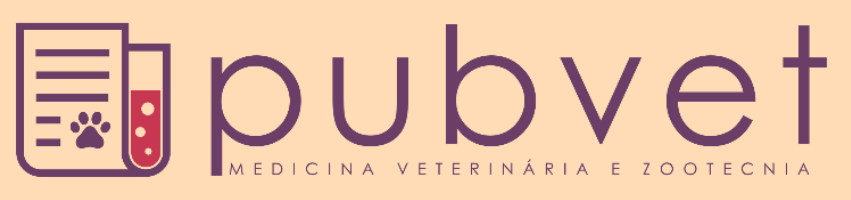

https://doi.org/10.31533/pubvet.v13n3a276.1-14

\title{
Caracterização da variabilidade espacial dos índices de conforto animal em sistemas de confinamento Compost Barn
}

\author{
Vania Corrêa Mota ${ }^{1 *}$, Ednilton Tavares de Andrade ${ }^{2} \theta$, Daniel Furtado Leite ${ }^{3}$ \\ ${ }^{I}$ Professora Adjunta, Departamento de Matemática e Estatística, Universidade Federal de Rondônia - UNIR, Campus de Ji-Paraná-RO, Brasil \\ ${ }^{2}$ Professor Titular, Departamento de Engenharia Agrícola, Universidade Federal Lavras - UFLA, Lavras - MG, Brasil. \\ ${ }^{3}$ Professor Adjunto, Departamento de Automática, Universidade Federal Lavras - UFLA, Lavras - MG, Brasil. \\ *Autor para correspondência, E-mail: vaniamota33@gmail.com
}

\begin{abstract}
Resumo. O estudo a respeito do quanto os fatores ambientais e o microclima das instalações de bovinos leiteiros influência no desempenho da produção do animal tem ganhado espaço no meio científico e prioridade do ponto de vista dos produtores. Este estudo tem como objetivo utilizar a modelagem geoestatística para representar e localizar os pontos críticos dos índices de conforto animal do ambiente térmico no interior de galpões de confinamento para bovinos leiteiros no modelo Compost Barn. A pesquisa foi realizada em um confinamento Compost Barn localizado no município de Três Corações em Minas Gerais durante o verão e o inverno de 2016. Foram determinados os índices de temperatura e umidade, temperatura de globo negro, carga térmica radiante e entalpia. Os resultados foram submetidos à análise geoestatística para verificação da variabilidade espacial dos dados por meio de semivariogramas e mapas de krigagem. A modelagem mostrou-se eficiente para representar e estudar o microclima no interior de galpões. Os mapas dos índices estimados por krigagem ordinária permitiu visualizar a condição do ambiente interno na área de descanso do gado em confinamento Compost Barn. Os mapas mostram pontos específicos de desconforto para vacas leiteiras.
\end{abstract}

Palavras chave: ambiência, bem-estar animal, bovinos leiteiros, modelagem geoestatística

\section{Characterization of the spatial variability of animal comfort indices within Compost Barn containment systems}

\begin{abstract}
The study about how environmental factors and the microclimate of dairy cattle facilities influence the performance of the animal's production has gained space in the scientific environment and priority from the point of view of producers. The objective of this article is to use geostatistical modeling to represent and locate the critical points of the indices of animal comfort of the thermal environment inside confinement sheds for dairy cattle in the Compost Barn model. This research was carried out in a Compost Barn confinement, located in the municipality of Três Corações in the state of Minas Gerais during the summer and winter of 2016. The temperature and humidity, black globe temperature and humidity indices, radiant thermal charge and enthalpy were determined. The results were subject to geostatistical analysis to verify the spatial variability of the data, through the use of semivariograms and kriging maps. The modeling proved to be efficient to represent and study the microclimate inside sheds. Maps of indices estimated by ordinary kriging allow visualization of internal environment conditions in the cattle resting area considering Compost Barn confinement. The maps show specific points of discomfort for dairy cows.
\end{abstract}

Keywords: ambience, animal welfare, dairy cattle, geostatistical modeling 


\title{
Caracterización de la variabilidad espacial de los índices de conforto animal en sistemas de confinamiento Compost Barn
}

\begin{abstract}
Resumen. El estudio acerca de cuánto los factores ambientales y el microclima de las instalaciones de bovinos lecheros influencian en el desempeño de la producción del animal ha ganado espacio en el medio científico y prioridad desde el punto de vista de los productores. Este estudio tiene como objetivo utilizar el modelado geoestadístico para representar y localizar los puntos críticos de los índices de conforto animal del ambiente térmico en el interior de galpones de confinamiento para bovinos lecheros en el modelo Compost Barn. La investigación fue realizada en un confinamiento Compost Barn ubicado en el municipio de Tres Corazones en Minas Gerais durante el verano y el invierno de 2016. Se determinaron los índices de temperatura y humedad, temperatura de globo negro, carga térmica radiante y entalpía. Los resultados fueron sometidos al análisis geoestadístico para verificar la variabilidad espacial de los datos por medio de semivariogramas y mapas de kriging. El modelado se mostró eficiente para representar y estudiar el microclima en el interior de galpones. Los mapas de los índices estimados por kriging ordinario permitieron visualizar la condición del ambiente interno en el área de descanso del ganado en confinamiento Compost Barn. Los mapas muestran puntos específicos de incomodidad para las vacas lecheras.
\end{abstract}

Palabras clave: ambiente, bienestar animal, bovinos lecheros, modelado geoestadístico

\section{Introdução}

$\mathrm{O}$ estudo a respeito do quanto os fatores ambientais e o microclima das instalações de bovinos leiteiros influência no desempenho na produção animal tem ganhado espaço no meio científico e prioridade do ponto de vista dos produtores e investidores. A ideia é que os animais sejam alojados em condições ideais para que possam expressar todo o seu potencial genético.

Em sistemas de confinamento, as vacas são alimentadas no cocho e necessitam de instalações confortáveis, tais como: Loose Housing, Tie Stall; Free Stall e Compost Barn (Eckelkamp et al., 2016; Mota et al., 2017). O modelo Compost Barn (CB) (Black et al., 2014; Ferreira, 2015; Leso et al., 2013; Mota et al., 2018; Pilatti \& Vieira, 2017) tem sido o modelo preferido por produtores. Apesar do aumento da popularidade do sistema CB no Brasil, o conhecimento científico sobre esse sistema é escasso, necessitando, portanto, de mais estudos que possam auxiliar os produtores de leite no processo de tomada de decisão e planejamento. Neste contexto, a necessidade de entendimento, análise e controle do microclima do ambiente interno nas instalações para confinamento de gado leiteiro é a principal razão para se buscar métodos de modelagem matemática e de representação e processamento computacional. Os métodos de modelagem considerados neste artigo, são os métodos de modelagem geoestatística, como aqueles apresentados por Faria et al. (2008), Silva et al. (2012) e Gonçalves et al. (2016).

Estudar e avaliar a variabilidade espacial do microclima de galpões de confinamento é necessário para controlar e corrigir problemas de instalação e para monitorar as condições de estresse térmico (Gonçalves et al., 2016; Medeiros et al., 2014). Diante disso, este artigo tem como objetivo, utilizar a modelagem geoestatística, para representar e localizar os pontos críticos dos índices de conforto animal do ambiente térmico no interior de galpões de confinamento para bovinos leiteiros no modelo Compost Barn.

\section{Material e métodos}

A pesquisa foi realizada em um confinamento para bovinos leiteiros em uma propriedade rural do município de Três Corações em Minas Gerais. Segundo a classificação internacional de Köppen \& Geiger (1928), o clima da região é do tipo CWA, caracterizado por duas estações bem definidas: uma seca e de menores temperaturas, que se estende de maio a setembro, e outra úmida e de temperaturas mais elevadas, de outubro a abril. A temperatura média anual é de $20,2^{\circ} \mathrm{C}$, e a precipitação anual é de $1.401 \mathrm{~mm}$. A temperatura média do ar e a umidade relativa externa do galpão durante os dias de coleta dos dados foram obtidos por meio da estação meteorológica portátil modelo $\mathrm{N}^{\circ} \mathrm{ITWH}-1080$ da Instrutemp (precisão de \pm $1^{\circ} \mathrm{C} ; 5 \% \mathrm{UR} ; \mathrm{e} \pm 1 \mathrm{~m} / \mathrm{s}$ ) com sensores apropriados para coletar e armazenar os dados. 
O galpão, em sistema de confinamento modelo Compost Barn (CB) com orientação Noroeste/Sudoeste, possui 18,7 metros de largura por 50,0 metros de comprimento, pé direito 4 metros e cumeeira de 6 metros. Destes, 13,0 m x 50,0 m são destinados à área de descanso com cama. Esta área é dividida em 3 lotes (alta, média e baixa produção de leite), separados por meio de cerca elétrica. Esta é a área utilizada para análise. Há ainda um corredor de alimentação, medindo $3 \mathrm{~m}$ x $50 \mathrm{~m}$, com um comedouro (cocho de volumoso) em toda a extensão do galpão; e outro corredor medindo $2 \mathrm{~m}$ x $50 \mathrm{~m}$, com 4 bebedouros medindo $0.50 \mathrm{~m}$ x $2 \mathrm{~m}$ (fundo formato trapézio) com capacidade para 300 litros de água. Existem 3 cochos de mineral e 5 ventiladores de 6 hélices centralizados, a 3.20 metros de altura, na área de descanso que proporcionam uma vazão de $48.000 \mathrm{~m}^{3} \mathrm{de}$ ar por hora cada (Figura 1).

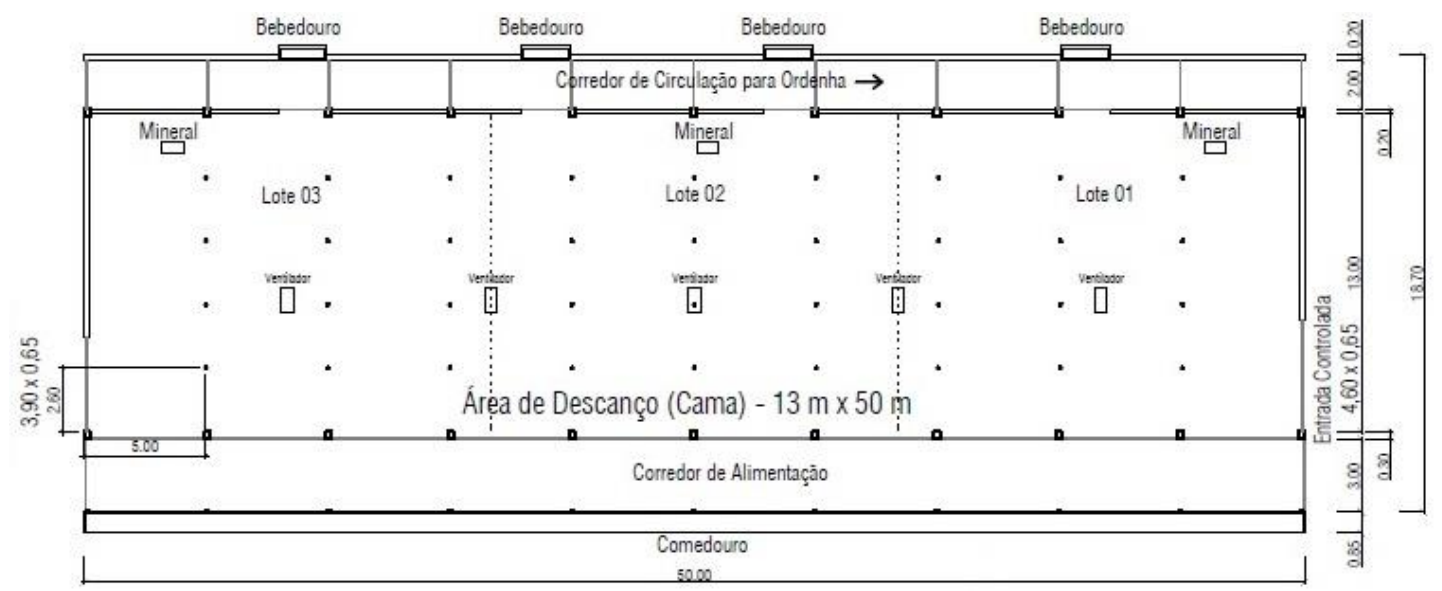

Figura 1. Planta baixa do galpão Compost Barn.

O experimento foi conduzido durante o verão de 2016 - tratamento (VER) e inverno de 2016 tratamento (INV) e foi dividido em 6 períodos com 3 dias de coleta em VER (P1, P2 e P3) e 3 dias de coleta em INV (P4, P5 e P6). Os registros de dados foram realizados em janeiro de 2016, nos dias 17 no P1; 24 no P2; 31 no P3; e no mês de julho, nos dias 17 no P4; 24 no P5; 31 no P6, duas vezes ao dia, nos horários de 9 horas e de 15 horas, com os ventiladores ligados e desligados. Foram coletadas 36 amostras, para as variáveis, temperatura do ar, umidade relativa, velocidade do ar, ponto de orvalho e temperatura do globo negro, em uma malha regular (Yamamoto \& Landim, 2013) com 36 pontos georeferenciados. Os pontos são distribuídos uniformemente ao longo do galpão com espaçamento de $2.6 \mathrm{~m}$ por $5 \mathrm{~m}$. Para a realização das medições das variáveis climáticas, os equipamentos estavam a 1.8 $\mathrm{m}$ do piso (cama), em cada posição da malha regular de pontos (Figura 1).

O equipamento utilizado para o registro de dados foi o sensor portátil da marca Kestrel ${ }^{\circledR}$, modelo 3000 , com faixa de registro de velocidade do ar e umidade com precisão de $\pm 3 \%$ da leitura; temperatura (precisão de $\pm 1^{\circ} \mathrm{C}$ ), ponto de orvalho (precisão de $\pm 3^{\circ} \mathrm{C}$ ) e temperatura do bulbo úmido (precisão de $\pm 2^{\circ} \mathrm{C}$ ). A temperatura do globo negro foi registrada por meio de um medidor de temperatura digital, sensor externo (Termopar tipo K) inserido no centro do globo negro (esfera oca com $7 \mathrm{~cm}$ de diâmetro e pintada de preto fosco), coletados manualmente.

A partir dos dados medidos nos horários pré-determinados foram obtidos os índices de Temperatura e Umidade (ITU), que associam a temperatura de bulbo seco e a temperatura do bulbo úmido; o índice de temperatura de globo negro e umidade (ITGU), índice de Carga Térmica Radiante (CTR), e a Entalpia (H).

Os índices de temperatura e umidade (ITU) de conforto térmico foram determinados pela seguinte Eq. 1 citado por Avila et al. (2013):

$I T U=0,7\left(T_{b s}+T_{b u}\right)+40,6$

em que $T_{b s}$ é a temperatura de bulbo seco $\left({ }^{\circ} \mathrm{C}\right)$; e $T_{b u}$ é a temperatura de bulbo úmido $\left({ }^{\circ} \mathrm{C}\right)$.

O índice de globo negro e umidade (ITGU) foram desenvolvidos como um índice de conforto térmico para vacas leiteiras expostas à radiação solar direta e indireta. A fórmula é dada conforme Eq. 2, citado em Moura et al. (2010): 
$I T G U=T_{g}+0,36 T_{p o}+41,5$,

em que $T_{g}$ é a temperatura do globo negro $\left({ }^{\circ} \mathrm{C}\right)$; e $T_{p o}$ é a temperatura do ponto de orvalho $\left({ }^{\circ} \mathrm{C}\right)$.

O Índice de Carga Térmica Radiante (CTR) foi calculado segundo Eq.3 citado por Avila et al. (2013):

$C T R=\sigma(T R M)^{4}$,

em que $\sigma$ é a constante de Stefan-Boltzmann, $5.67 \times 10^{-8} W \cdot m^{-8} K^{-4}$, e TRM é a temperatura média radiante definida por Eq.4:

$T R M=100 \sqrt[4]{2,51 \sqrt{v v}\left(T_{g}-T_{b s}\right)+\left(\frac{T_{g}}{100}\right)^{4}}$,

em que, $v v$ é a velocidade do vento $\left(m s^{-1}\right) ; T_{g}$ é a temperatura do globo negro $\left({ }^{\circ} \mathrm{C}\right)$; e $T_{b s}$ é a temperatura de bulbo seco $\left({ }^{\circ} \mathrm{C}\right)$. Já a entalpia foi calculada a partir da Eq. 5 citado por Barnabé et al. (2015):

$H=1,006 T_{b s}+\left(\frac{U R}{P_{a t m}} * 10^{\frac{7.5 * T_{b s}}{237.3+T_{b s}}}\right)\left(71,28+0,052 T_{b s}\right)$,

onde $H$ é a entalpia ( $\mathrm{kj} \mathrm{kg}^{-1}$ ar seco); $T_{b s}$ é a temperatura de bulbo seco $\left({ }^{\circ} \mathrm{C}\right)$; e $U R$ é a umidade relativa $(\%), P_{a t m}$ é a pressão atmosférica em $\mathrm{mm} \mathrm{Hg}$.

Inicialmente os dados para todos os dias de coleta do verão e do inverno foram analisados por meio dos procedimentos da análise de estatística descritiva, sendo determinado à média, o desvio padrão, o coeficiente de variação e os valores de máximo de mínimo (Banzatto \& Kronka, 2015). Posteriormente, os resultados dos índices foram submetidos à modelagem geoestatística para verificar a variabilidade espacial dos dados, por meio da construção dos semivariogramas e de mapas de krigagem.

Os semivariogramas foram estimados por meio dos estimadores clássico de Matheron conforme Eq.6 citado por Queiroz et al. (2017):

$\hat{\gamma}(h)=\frac{1}{2 N(h)} \sum_{j=1}^{N(h)}\left[z\left(x_{j}+h\right)-z\left(x_{j}\right)\right]^{2}$,

em que $N(h)$ é o número de pares possíveis para a distância $h ; \hat{\gamma}(h)$ é a semivariância para uma distância $h ; z\left(x_{j}\right)$ e $z\left(x_{j}+h\right)$ são as observações dos índices de conforto animal separadas pelo vetor $h$; e $h$ é a distância de separação das observações.

Para o ajuste do semivariograma teórico, foi utilizado o método dos mínimos quadrados ordinários (OLS). Os modelos estatísticos isotrópicos comparados foram: esférico, gaussiano, exponencial e linear, conforme (Yamamoto \& Landim, 2013). Do conjunto de resultados obtidos pelos estimadores clássicos para os três modelos foram estimados seus parâmetros e selecionado o melhor modelo de acordo com a aproximação para o valor do Critério de Akaike (Akaike, 1974) (AIC) proposta por Webster \& Oliver (2001). AIC é dado conforme Eq.7:

$|A I C|=2 p+n \cdot \ln \left(\frac{R S S}{n}\right)$,

em que $n$ é o número de observações; $p$ é o número de parâmetros; e RSS é a soma dos quadrados dos resíduos. O melhor modelo apresentar menor valor de AIC. A relação apresentada na Eq.8:

$\left(\frac{C o}{C o+C 1}\right) \times 100$

em que $C o$ é o efeito pepita; $C o+C$ é o patamar; foi utilizada para avaliar o grau de dependência espacial (DE) das variáveis, conforme Cambardella et al. (1994). Este classifica como forte, moderada e fraca a DE, quando se tem um efeito pepita $<25 \%$, entre 25 e $75 \%$, e acima de $75 \%$ do patamar, respectivamente. Se a relação for maior que $100 \%$, então a variável é considerada independente espacialmente.

Havendo dependência espacial, o interesse está na estimação de valores não amostrados, sem tendência e com variância mínima. O objetivo é obter um detalhamento da variável por meio de mapas suavizados. Nestes casos, é preciso utilizar algum interpolador geoestatístico para gerar essa superfície suavizada dos mapas de contorno. Dentre os diversos interpoladores existentes na literatura foi utilizado 
a krigagem ordinária (Yamamoto \& Landim, 2013). As análises foram realizadas no software GS + (Gamma, 2018).

\section{Resultados e discussão}

Os índices indicadores das condições microclimáticas foram calculados com o intuito de se avaliar a adequação do ambiente térmico à zona de conforto predefinida para as vacas leiteiras no ambiente da instalação em modelo Compost Barn. Os valores médios de temperatura externa no verão e inverno de 2016 foram de $26,5^{\circ} \mathrm{C}$ e $21,2^{\circ} \mathrm{C}$, respectivamente. Os valores médios de umidade foram $72 \%$ no verão e 58\% no inverno. Na Tabela 1 estão apresentados os resultados da estatística descritiva dos dados. A variabilidade dos dados é relativamente baixa para os índices ITGU, ITU CTR e a H, com valores variando de $0.7 \%$ a $7.0 \%$ para a CTR no verão às 9:00 horas com ventiladores ligados. Para os ventiladores desligados às 9:00 e às 15:00 horas, os valores do coeficiente de variação se encontram nesse intervalo. Os valores de máximo e mínimo para a ITGU no verão indicam que os animais encontram-se em situação de perigo podendo acarretar baixo rendimento (Moura et al., 2010), isso foi verificado às 9:00 horas e às 15:00 horas; porém no período da tarde o maior valor de ITGU foi observado com os ventiladores desligados, o que reforça a importância da utilização da ventilação forçada (mecânica).

Tabela 1. Estatística dos índices de Temperatura e Umidade (ITU), índice de temperatura de globo negro e umidade (ITGU), índice de Carga Térmica Radiante (CTR) e a Entalpia (H) estudados em estábulos com sistema modelo Compost Barn no verão de 2016 com os ventiladores ligados e desligados

\begin{tabular}{|c|c|c|c|c|c|c|c|c|}
\hline \multirow[b]{3}{*}{ Estatísticas } & \multicolumn{8}{|c|}{ Verão } \\
\hline & \multicolumn{4}{|c|}{ 9:00 h- Ventiladores ligados } & \multicolumn{4}{|c|}{ 9:00 h - Ventiladores desligados } \\
\hline & CTR & ITGU & Entalpia & ITU & CTR & ITGU & Entalpia & ITU \\
\hline Média $(\bar{x})$ & 468.6 & 80.7 & 66.1 & 72.7 & 463.1 & 80.7 & 67.1 & 72.7 \\
\hline S & 32.9 & 1.9 & 1.3 & 0.5 & 26.2 & 1.56 & 1.63 & 0.6 \\
\hline $\mathrm{CV}$ & 7.0 & 2.4 & 1.9 & 0.7 & 5.6 & 1.9 & 2.43 & 0.8 \\
\hline Mínimo & 441.4 & 79.2 & 63.9 & 71.7 & 439.3 & 79.0 & 63.6 & 71.7 \\
\hline \multirow[t]{2}{*}{ Máximo } & 568.0 & 85.0 & 68.9 & 73.7 & 535.1 & 85.1 & 71.0 & 74.1 \\
\hline & \multicolumn{4}{|c|}{ 15:00 h - Ventiladores ligados } & \multicolumn{4}{|c|}{ 15:00 h - Ventiladores desligados } \\
\hline Média $(\bar{x})$ & 476.8 & 82.8 & 68.4 & 74.5 & 471.7 & 83.9 & 70.7 & 75.5 \\
\hline$S$ & 18.3 & 1.0 & 4.2 & 1.5 & 15.9 & 1.7 & 2.9 & 0,9 \\
\hline $\mathrm{CV}$ & 3.8 & 1.3 & 6.2 & 1.9 & 3.4 & 2.1 & 4.1 & 1.2 \\
\hline Mínimo & 448.8 & 81.3 & 58.7 & 70.5 & 396.8 & 77.9 & 66.2 & 74.0 \\
\hline Máximo & 576.7 & 85.2 & 81.1 & 79.2 & 508.7 & 90.1 & 77.3 & 77.4 \\
\hline
\end{tabular}

C. V. = Coeficiente de Variação, S = Desvio padrão.

Os ventiladores são recomendados para sistemas de confinamento no modelo Compost Barn, para auxiliam na circulação do ar no interior do galpão, na área de descanso dos animais, removendo o calor e a umidade, além de ser indicado para ajudar a secar o material de cama utilizado (Endres \& Barberg, 2007; Endres \& Janni, 2008). O material de cama mais seco retarda o crescimento bacteriano e manterá as vacas mais limpas, uma vez que as camas secas não aderem às superfícies das tetas ou as pernas dos animais.

Adotou-se a tabela de ITU para bovinos leiteiros de alta produção proposta por (Ferreira, 2015) em que, ITU abaixo de 68 indica sem estresse; de 69 a 71 indica um leve estresse; de 72 a 79 indica um estresse ameno; de 79 a 89 indica um estresse moderado; e de 90 a 98 indica um estresse grave. $O$ valor médio de ITU às 9:00 h foi de 72.7, valor este similar ao encontrado tanto em situações de ventilação forçada. O ITU apresentou um conforto térmico para os animais, com um estresse considerado ameno (Ferreira, 2015). Porém, quando foram observados os valores de máximo e mínimo, verificou-se que existem pontos na área de descanso que representa situação de alerta (Avila et al., 2013). Às 15:00 h, os valores de ITU aumentaram representando situação de alerta, porém com valores médios ainda no intervalo de estresse ameno. O valor de máximo apresentou um estresse moderado podendo ocasionar baixo rendimento na produção de leite. 
As trocas térmicas por radiação entre o animal e o ambiente foram avaliadas pela CTR. No verão os valores médios de CTR, como descritos na Tabela 1, foram registrados nos horários das 9:00 e 15:00 h. Semelhante ao que ocorreu com o ITGU e o ITU, houve um aumento da CTR entre às 9:00 e 15:00 h, que passou de $468.6 \mathrm{~W} \mathrm{~m}^{-2}$ às 9:00 $\mathrm{h}$, para $476.8 \mathrm{~W} \mathrm{~m}^{-2}$ às 15:00 h com os ventiladores ligados e de $463.1 \mathrm{~W} \mathrm{~m}^{-2}$ para $471.7 \mathrm{~W} \mathrm{~m}^{-2}$, respectivamente às 9:00 e 15:00 h para os ventiladores desligados. Esses dados se assemelham aos encontrados por Kawabata et al. (2005) que citam valores médios de CTR no horário das 8:00 h que variaram de 454.84 a $484.30 \mathrm{~W} \mathrm{~m}^{-2}$.

No inverno os resultados do coeficiente de variação foram semelhantes aos resultados do verão (Tabela 2). Existe uma baixa dispersão em torno da média, o que representa baixa variabilidade dos dados. Os valores de C.V. para o CTR, ITGU e ITU, tanto as 9:00 h quanto às 15:00 h com os ventiladores ligados e desligados se encontram abaixo de $11.9 \%$; enquanto que, para a $\mathrm{H}$ foram encontrados valores de CV de $10.2 \%$ no período da tarde.

Tabela 2. Estatística dos índices de Temperatura e Umidade (ITU), índice de temperatura de globo negro e umidade (ITGU), índice de Carga Térmica Radiante (CTR) e a Entalpia (H) estudados em estábulos com sistema modelo Compost Barn no inverno de 2016 com os ventiladores ligados e desligados.

\begin{tabular}{|c|c|c|c|c|c|c|c|c|}
\hline \multirow[b]{3}{*}{ Estatísticas } & \multicolumn{8}{|c|}{ Inverno } \\
\hline & \multicolumn{3}{|c|}{ 9:00 h- Ventiladores ligados } & \multicolumn{5}{|c|}{ 9:00 h- Ventiladores desligados } \\
\hline & CTR & ITGU & Entalpia & ITU & CTR & ITGU & Entalpia & ITU \\
\hline Média $(\bar{x})$ & 485.4 & 73.9 & 44.4 & 63.8 & 460.9 & 73.4 & 43.9 & 63.1 \\
\hline S & 57.8 & 2.5 & 1.1 & 0.6 & 38.9 & 2.4 & 2.1 & 1.0 \\
\hline C. V. & 11.9 & 3.3 & 2.4 & 0.9 & 8.4 & 3.2 & 4.8 & 1.6 \\
\hline Mínimo & 404.7 & 70.8 & 41.9 & 61.9 & 415.5 & 70.5 & 40.8 & 61.6 \\
\hline \multirow[t]{2}{*}{ Máximo } & 614.0 & 79.1 & 46.5 & 64.6 & 568.7 & 80.5 & 50.7 & 66.2 \\
\hline & \multicolumn{3}{|c|}{ 15:00 h- Ventiladores ligados } & \multicolumn{5}{|c|}{ 15:00 h- Ventiladores desligados } \\
\hline Média $(\bar{x})$ & 451.6 & 75.4 & 46.6 & 65.5 & 448.8 & 78.0 & 55.8 & 69.3 \\
\hline S & 17.4 & 0,7 & 2.1 & 1.0 & 7.2 & 1.3 & 5.7 & 2.0 \\
\hline C. V. & 3.8 & 1.0 & 4.5 & 1.5 & 1.6 & 1.7 & 10.2 & 2.9 \\
\hline Mínimo & 365.6 & 73.2 & 43.6 & 63.6 & 438.8 & 76.1 & 47.4 & 65.8 \\
\hline Máximo & 475.9 & 76.9 & 51.7 & 67.8 & 469.6 & 81.5 & 68.2 & 72.8 \\
\hline
\end{tabular}

$\overline{\mathrm{CV}}=$ Coeficiente de Variação, $\mathrm{S}=$ Desvio padrão.

Em relação ao ITGU, o valor médio e o valor de mínimo às 9:00 h com e sem o uso da ventilação estão abaixo do intervalo de alerta, mas o valor de máximo encontra-se no intervalo de situação de perigo para os animais. Valores nessa faixa de perigo também foram encontrados por Araujo et al. (2016) ao estudar vacas mestiças (Holandesas e Gir) em lactação. Os autores recomendam que, em tais situações, existe a necessidade de intervenção humana, sendo esta por meio de instalações que promovam um ambiente de conforto para os animais, para que os mesmos respondam positivamente, expressando o seu máximo potencial na produção. Já para o ITGU, às 15 horas foram encontrados valores médios de 82,8, considerados como sendo situação de alerta nas situações de ventiladores ligados e valores médios com ventiladores desligados de 83,9 que também se encontram em situação de alerta, reforçando a necessidade da ventilação para melhorar a qualidade do ambiente interno do galpão (Avila et al., 2013). Os valores de máximo com e sem a utilização da ventilação se encontra em situação de perigo para as vacas leiteiras.

Os valores de ITU se encontram abaixo de 71, o que configura conforto térmico com estresse leve para os animais às 9:00 e às 15:00 h, com e sem o uso da ventilação. De um modo geral, no inverno pode-se considerar que os animais se encontravam em condições sem estresse, de acordo com os valores de referência de ITU para bovinos leiteiros de alta produção (Ferreira, 2015). Apenas quando não se utilizou a ventilação às 15:00 h, verificou-se um pequeno aumento do índice de estresse.

Durante o período da manhã foram encontrados valores médios de CTR de $485.4 \mathrm{~W} \mathrm{~m}^{-2} \mathrm{e} 460.9 \mathrm{~W}$ $\mathrm{m}^{-2} \mathrm{com}$ ventiladores ligados e desligados respectivamente, estes valores foram maiores do que os encontrados à tarde, de modo geral são desejáveis os menores valores possíveis de CTR. Os materiais utilizados na construção da instalação influência nos resultados da CTR, bem como os efeitos dos ventos 
e da temperatura (Ferreira, 2015), neste caso são indicados à construção de instalações bem planejadas, seguindo os critérios para a orientação da construção do galpão.

Em resumo, observaram aumentos no período da tarde nos resultados de ITU, ITGU e H em consequência ao aumento da temperatura nas duas estações analisadas. Houve também uma pequena elevação desses índices no verão em relação ao inverno, refletindo a alteração climática, o que já era esperado.

Devido à ocorrência de estressores ambientais em instalações animais em sistemas intensivos de produção, muitos estudos têm investigado o estresse térmico da produção leiteira por meio da modelagem geoestatística. Na tabela 3 e 4 estão apresentados os resultados dos parâmetros dos semivariogramas isotrópicos, i.e., idênticos em todas as direções, para às variáveis estudadas que apresentaram os menores valores de aproximação do critério de Akaike (1974).

Para o ITGU, CTR, H e o ITU no verão de 2016 às 9:00 h, obtidos com os ventiladores ligados, foi verificado uma forte dependência espacial, com melhor ajuste dos modelos gaussiano para a CTR e esférico para as demais variáveis estudadas. Ajustes de modelos esféricos estão de acordo com resultados encontrados em Silva et al. (2012) que, estudando a temperatura do ar na sala de pré-ordenha de um confinamento Free-Stall com sistema adiabático evaporativo, obtiveram melhor ajuste para este modelo teórico.

Tabela 3. Resultado do critério de aproximação de Akaike (AIC) e do grau de dependência espacial (DE) dos modelos e parâmetros ajustados aos semivariogramas experimentais, relativos ao índice de Temperatura e Umidade (ITU), índice de temperatura de globo negro e umidade (ITGU), índice de Carga Térmica Radiante (CTR) e a Entalpia, com os ventiladores ligados e ventiladores desligados às 9:00 e às 15:00 horas no verão de 2016

\begin{tabular}{|c|c|c|c|c|c|c|}
\hline Îndices & Modelo & Efeito pepita & Patamar & Alcance & $\mathrm{DE}(\%)$ & $\mathrm{AIC}$ \\
\hline & \multicolumn{6}{|c|}{ Verão - 9:00 horas - Ventiladores ligados } \\
\hline CTR & Gaus. & 148.00 & 1139.00 & 4.07 & 12.99 & 427.62 \\
\hline ITGU & Sph. & 0.15 & 3.90 & 4.39 & 3.84 & 20.19 \\
\hline Entalpia & Sph. & 0.011 & 1.85 & 4.18 & 6.43 & 6.59 \\
\hline \multirow[t]{2}{*}{ ITU } & Sph. & 0.01 & 0.29 & 5.20 & 3.45 & -199.64 \\
\hline & \multicolumn{6}{|c|}{ Verão - 9:00 horas -Ventiladores Desligados } \\
\hline CTR & Exp. & 1.00 & 614.00 & 4.71 & 0.16 & 477.04 \\
\hline ITGU & Exp. & 0.74 & 2.81 & 20.67 & 26.33 & 84.17 \\
\hline Entalpia & Gaus. & 0.001 & 2.64 & 4.18 & 0.04 & 8.86 \\
\hline \multirow[t]{2}{*}{ ITU } & Gaus. & 0.001 & 0.38 & 5.65 & 0.26 & -86.58 \\
\hline & \multicolumn{6}{|c|}{ Verão - 15:00 horas -Ventiladores ligados } \\
\hline CTR & EPP & - & - & - & - & - \\
\hline ITGU & Gaus. & 0.53 & 1.57 & 29.30 & 33.76 & -55.14 \\
\hline Entalpia & Exp. & 7.59 & 36.17 & 33.76 & 20.98 & 48.3 \\
\hline \multirow[t]{2}{*}{ ITU } & Sph. & 0.001 & 1.73 & 6.99 & 0.06 & -2.85 \\
\hline & \multicolumn{6}{|c|}{ Verão - 15:00 horas - Ventiladores desligados } \\
\hline CTR & EPP & - & - & - & - & - \\
\hline ITGU & EPP & - & - & - & - & - \\
\hline Entalpia & Lin. & 5.99 & 8.77 & 17 & 68.30 & 24.3 \\
\hline ITU & Sph. & 0.30 & 1.87 & 152.07 & 16.04 & -93.30 \\
\hline
\end{tabular}

Sph. = esférico, Gaus.= gaussiano, Exp. = exponencial, Lin.= linear; EPP = efeito pepita puro.

Nesse mesmo horário (9:00 h) com os ventiladores desligados verificou-se melhor ajuste do modelo exponencial para o ITGU, com moderada dependência espacial, e para o ITU, CTR e entalpia observouse uma forte dependência espacial conforme classificação de Cambardella et al. (1994), com melhor ajuste dos modelos gaussiano, exponencial e gaussiano respectivamente.

Verificou não haver dependência espacial para o CTR às 15:00 com e sem o uso da ventilação, para o ITGU com os ventiladores ligados também ocorreu o efeito pepita puro. Conclui-se, portanto, que a distribuição espacial para CTR e ITGU no interior do galpão nesse horário é aleatória e as amostras, 
para a malha amostrada são independentes. Já o ITGU com o uso da ventilação forçada apresentou moderada dependência espacial com valor de $33,8 \%$ e ajuste do modelo exponencial. A entalpia e o ITU apresentaram às 15:00 h com ventiladores ligados ajustes para os modelos exponencial e esférico respectivamente com uma forte dependência espacial. Nesse horário sem ventilação a entalpia apresentou uma moderada dependência espacial com melhor ajuste do modelo linear, enquanto o ITU também apresentou melhor ajuste com o modelo e exponencial com forte dependência espacial

Os resultados da análise geoestatística no inverno de 2016 às 9:00 h com os ventiladores ligados mostraram que as variáveis apresentaram forte DE com melhor ajuste do modelo esférico para a CTR e o ITU e para a entalpia verificou melhor ajuste do modelo gaussiano (Tabela 4).

O ITGU ajustou-se ao modelo linear com fraca dependência espacial. Nesse horário, quando utilizou o sistema de ventilação o modelo apropriado para descrever o comportamento espacial da ITGU e da CTR foi o modelo de efeito pepita puro. O efeito pepita puro reflete um fenômeno que não é totalmente conhecido, por falta de informação, como variações locais, erros de amostragem entre outros e também revela a descontinuidade do semivariograma para distâncias menores do que a menor distância entre as amostras (Silva et al., 2012; Yamamoto \& Landim, 2013).

Tabela 4. Resultado do critério de aproximação de Akaike (AIC) e do grau de dependência espacial (DE) dos modelos e parâmetros ajustados aos semivariogramas experimentais, relativos ao índice de Temperatura e Umidade (ITU), índice de temperatura de globo negro e umidade (ITGU), índice de Carga Térmica Radiante (CTR) e a Entalpia, com ventiladores ligados e desligados às 9:00 e às 15:00 no inverno de 2016.

\begin{tabular}{|c|c|c|c|c|c|c|}
\hline Îndices & Modelo & Efeito pepita & Patamar & Alcance & $\mathrm{DE}(\%)$ & AIC \\
\hline & \multicolumn{6}{|c|}{ Inverno - 9:00 - Ventiladores ligados } \\
\hline$\overline{\mathrm{CTR}}$ & Sph. & 200.00 & 3563.00 & 5.59 & 5.61 & 633,83 \\
\hline ITGU & Lin. & 5.66 & 6.47 & 16.9 & 87.48 & 183.64 \\
\hline Entalpia & Gaus. & 0.001 & 1 & 2.98 & 0.1 & 6.41 \\
\hline \multirow[t]{2}{*}{ ITU } & Sph. & 0.001 & 0.25 & 5.45 & 0.40 & -121.95 \\
\hline & \multicolumn{6}{|c|}{ Inverno - 9:00 - Ventiladores desligados } \\
\hline CTR & EPP & - & - & - & - & - \\
\hline ITGU & EPP & - & - & - & - & - \\
\hline Entalpia & EPP & - & - & - & - & - \\
\hline \multirow[t]{2}{*}{ ITU } & Lin. & 0.001 & 0.84 & 2.60 & 0.12 & 22.24 \\
\hline & \multicolumn{6}{|c|}{ Inverno - 15:00 - Ventiladores ligados } \\
\hline CTR & Exp. & 10.2 & 285.3 & 5.04 & 3.57 & 372,69 \\
\hline ITGU & Exp. & 0.131 & 0.65 & 4.83 & 20.15 & $-35,47$ \\
\hline Entalpia & EPP & - & - & - & - & - \\
\hline \multirow[t]{2}{*}{ ITU } & EPP & - & - & - & - & - \\
\hline & \multicolumn{6}{|c|}{ Inverno - 15:00 - Ventiladores desligados } \\
\hline CTR & Gaus. & 5.6 & 72.2 & 22.9 & 7,76 & 203,45 \\
\hline ITGU & Sph. & 0.35 & 2.17 & 14.51 & 16,13 & $-8,20$ \\
\hline Entalpia & Gaus. & 4.5 & 37.84 & 4.83 & 11.89 & 149 \\
\hline ITU & Sph. & 0.01 & 5.39 & 16.23 & 0.18 & 34,05 \\
\hline
\end{tabular}

Sph. = esférico, Gaus.= gaussiano, Exp. = exponencial, Lin.= linear; EPP = efeito pepita puro.

O ITU apresentou forte dependência espacial, que pode ser descrita pelo modelo gaussiano. O modelo exponencial foi ajustado ao ITGU e ao CTR quando os ventiladores estavam ligados às 15:00 $\mathrm{h}$, enquanto o ITU e a entalpia apresentaram efeito pepita puro nessas condições. Quando os ventiladores foram desligados, verificou-se melhor ajuste dos modelos, esférico para o ITGU e o ITU e gaussiano para a CTR e entalpia. A relação entre o efeito pepita e o patamar, indica que a dependência espacial é forte às 15:00 horas. Os resultados que indicaram não haver dependência espacial optaram-se pela elaboração de mapas no intuído de auxiliar a visualização da condição microclimática na área de descanso do Compost Barn. 
A krigagem ordinária utilizada para interpolar os dados não amostrados produziu estimativas suavizadas para os índices ITGU, ITU, CTR e a entalpia. Esse efeito ocorre porque os valores mais altos são subestimados e os valores mais baixos, superestimados (Yamamoto \& Landim, 2013).

Os mapas de krigagem mostram essa suavização das estimativas para os índices de conforto animal, ITGU, ITU, CTR e da entalpia, no interior do galpão do sistema de confinamento para bovinos leiteiros no modelo Compost Barn (Figuras 2, 3, 4 e 5).
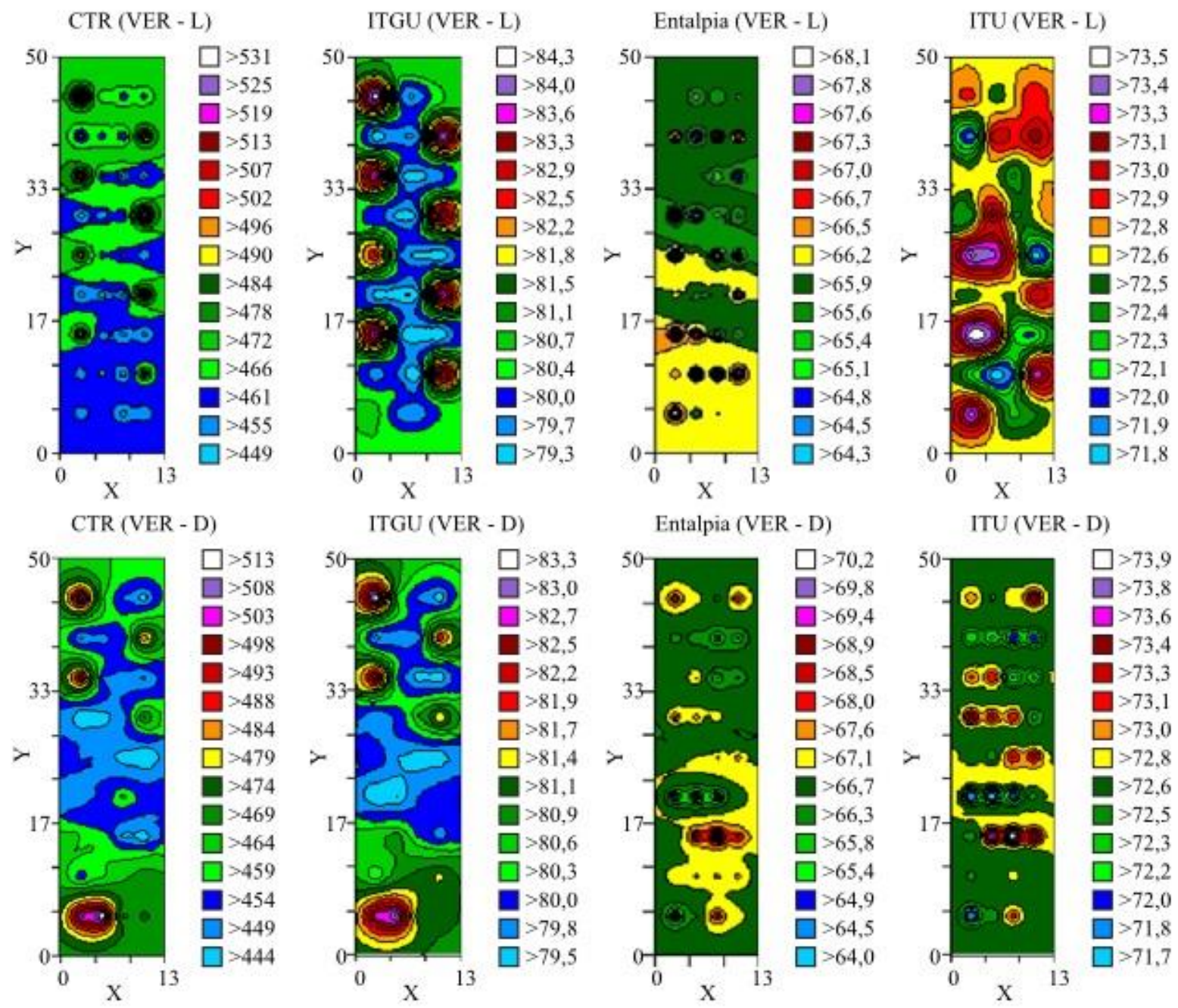

Figura 2. Mapas de krigagem relativos ao índice de Temperatura e Umidade (ITU), índice de temperatura de globo negro e umidade (ITGU), índice de Carga Térmica Radiante (CTR) e a Entalpia, com ventiladores ligados (L) e desligados (D) às 9:00 h no verão (VER) de 2016.

Com base nos mapas da figura 2, observou-se que valores de ITGU mais baixos, nas tonalidades de azul, se encontram na região central do galpão onde estão instalados os ventiladores, isso ocorre porque o ITGU combina os efeitos da temperatura, da umidade, da radiação e do vento em valor único (Ferreira, 2015). Quando os ventiladores foram desligados ocorre um espalhamento das tonalidades de azul, diminuindo às áreas com menores valores de ITGU. Verificaram-se nos mapas de CTR características semelhantes aos mapas de ITGU, quando não utilizou a ventilação. Para o ITU observou-se a formação de ilhas próxima a lateral da instalação quando os ventiladores estavam ligados e um padrão em quase toda a área quando não tinha ventilação forçada. A entalpia foi a que visualmente menos sofreu alteração no mapa, isso ocorreu devido à baixa variabilidade dos dados.

Pode-se observar na figura 3, que mesmo ligando os ventiladores para o CTR, entalpia, ITGU e ITU ocorreu um desconforto maior na área de descanso para os animais que vai do ponto inicial (zero) até aproximadamente $17 \mathrm{~m}$, mesmo havendo uma pequena variação do valores de CTR. Sem a ventilação forçada, verifica-se certa padronização nos mapas com maiores valores de entalpia e ITU depois dos 33 
m de comprimento do galpão. Para a CTR e ITGU confirma a homogeneidade dos dados devido a ausência de dependência espacial.
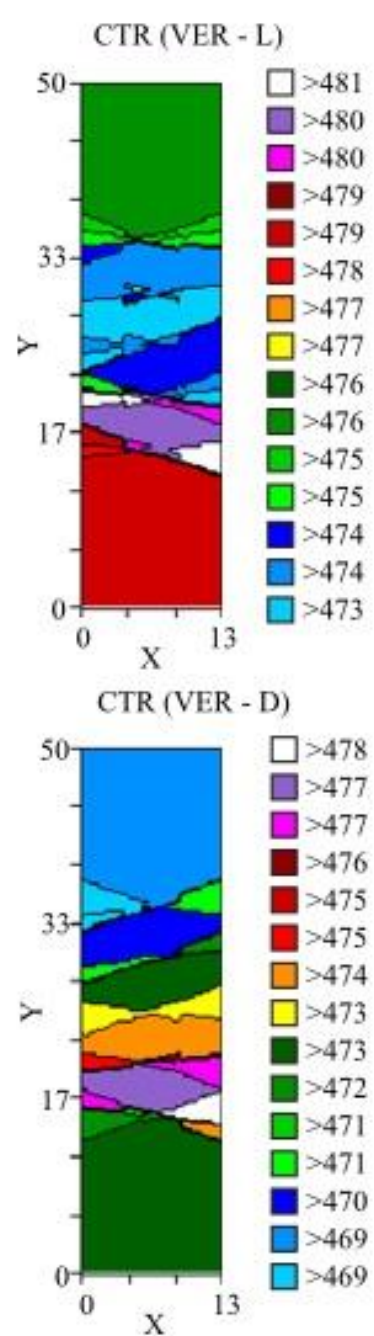

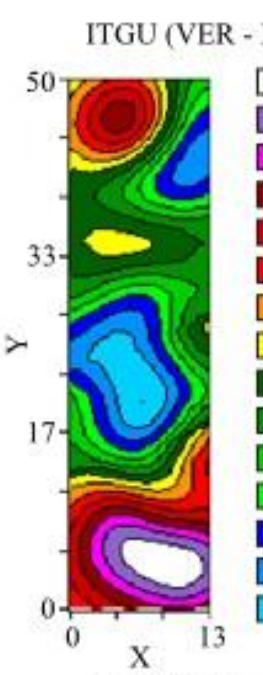

ITGU (VER - D)

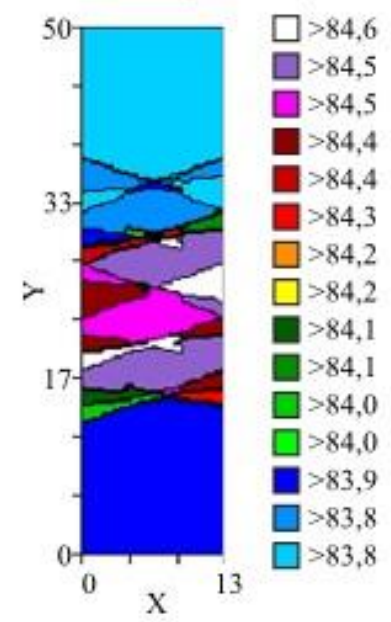

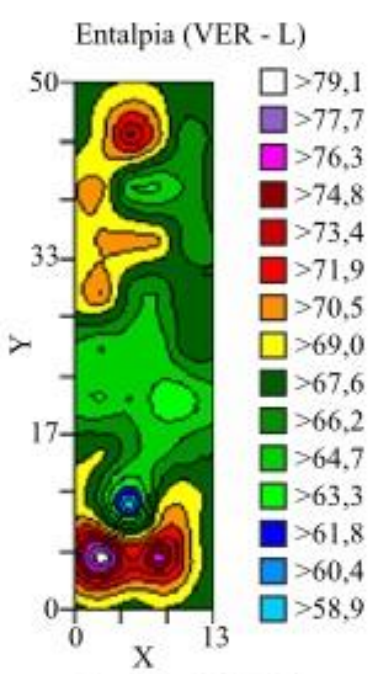

Entalpia (VER - D)

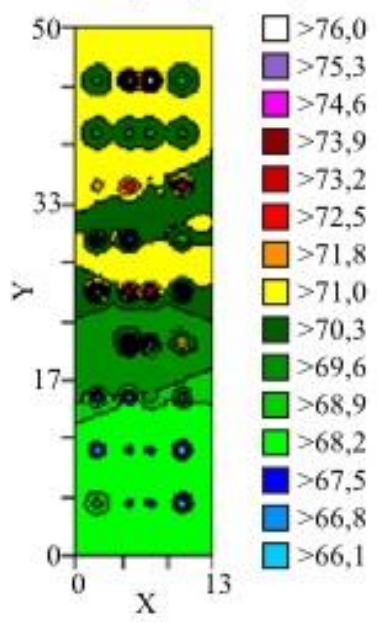

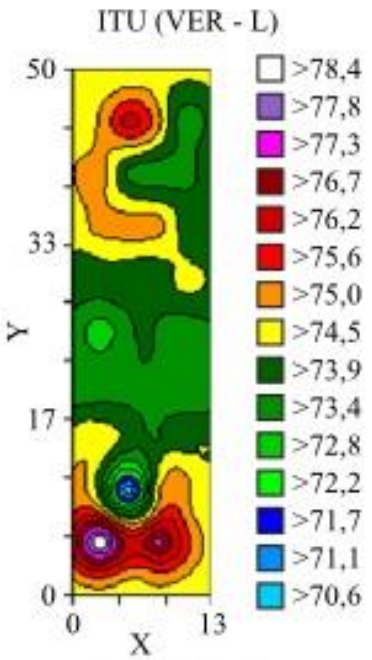

ITU (VER - D)

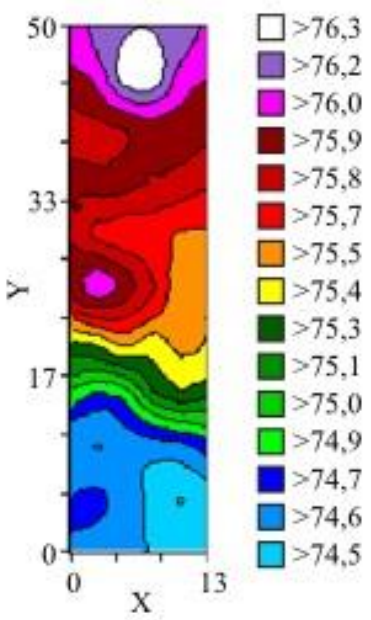

Figura 3. Mapas de krigagem relativos ao índice de Temperatura e Umidade (ITU), índice de temperatura de globo negro e umidade (ITGU), índice de Carga Térmica Radiante (CTR) e Entalpia com ventiladores ligados (L) e desligados (D) às 15:00 h no verão de 2016.

No inverno, (Figura 4) às 9:00 h, com os ventiladores ligados, pode-se verificar maiores valores de CTR próximos as laterais da área de descanso, com menores valores de CTR na região que existe maior circulação do ar. Isto comprova a influência da orientação da construção do galpão. A ITU apresenta ilhas, cor lilás a branca, com valores mais altos próximos aos $33 \mathrm{~m}$. Abaixo de $17 \mathrm{~m}$ são encontrados valores de entalpia menores, em azul. A entalpia correlaciona à temperatura e umidade no ambiente (Ferreira, 2015). Assim, quanto menor for o valor desse índice, menor será o calor no interior no galpão.

Quando a ventilação não existia, a CTR e o ITGU não apresentaram variação nos valores, com valores de ITU maiores, mas dentro do intervalo de conforto animal, próximo a entrada do galpão. A entalpia e o ITU apresentaram menores valores, indicando área de maior conforto para a vacas, na outra extremidade do galpão, onde existe uma baixa incidência dos raios solares nesse horário. Resultados semelhantes foram encontrados às $15: 00 \mathrm{~h}$, conforme pode ser verificado na figura 5 . Com os ventiladores ligados, ocorre maior circulação do ar. Por exemplo, para ITGU, quase toda a área do mapa apresentou a coloração próxima do tom vermelho, valores próximos da média, 75,4.

O ITU apresentou homogeneidade nos dados. Quando foram desligados os ventiladores, os resultados apresentaram pontos específicos, em branco, com maiores valores de ITU e ITGU, representando locais de desconforto para os animais. Maior valor de CTR foi encontrado na entrada do galpão, onde o sol da tarde alcança. 
Nos mapas de krigagem gerados (Figuras 2, 3, 4 e 5) é possível identificar as características dos índices avaliados, assim como fazer a análise de sua distribuição no interior do galpão ao longo da malha regular definida. Identificaram-se pontos críticos fora dos padrões de conforto e bem-estar animal usualmente recomendados. Estes resultados corroboram com os resultados encontrados em Faria et al. (2008) que por meio da modelagem geoestatística e da interpolação por krigagem concluíram que a descrição quantitativa da variabilidade espacial de atributos climáticos de galpões de confinamento para gado leiteiro em sistema Free Stall auxiliam no manejo correto desses animais.
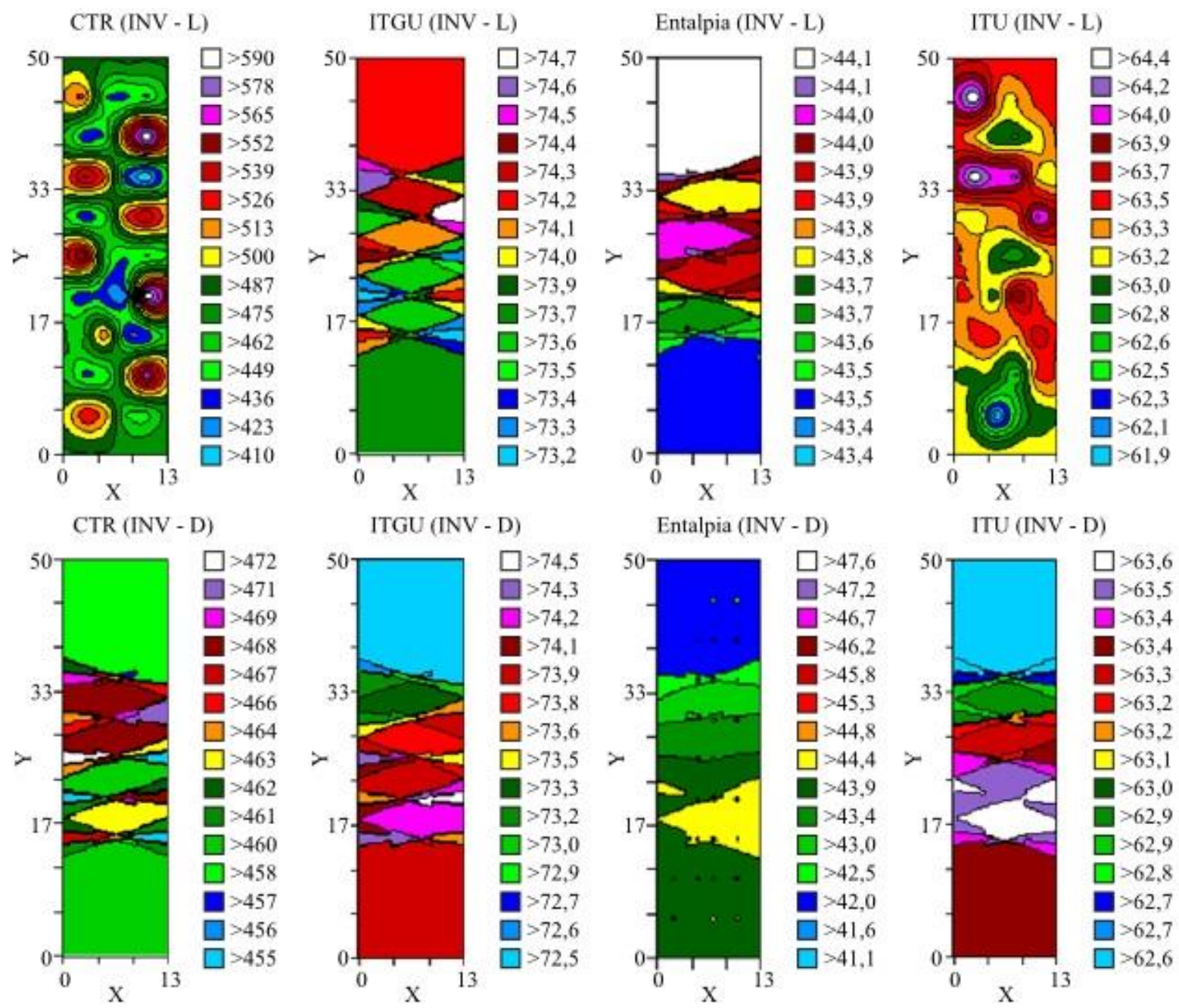

Figura 4. Mapas de krigagem relativos ao índice de Temperatura e Umidade (ITU), índice de temperatura de globo negro e umidade (ITGU), índice de Carga Térmica Radiante (CTR) e Entalpia com ventiladores ligados (L) e desligados (D) às 9:00 h no inverno de 2016.

Gonçalves et al. (2016) também ao estudarem a variabilidade espacial da temperatura do ar de um galpão Free Stall, utilizado para confinamento de bovinos leiteiros, verificaram que o uso da modelagem geoestatística, pode definir áreas especificas que apresentaram valores de temperatura acima do recomendado para o conforto térmico. Dessa forma, pode-se afirmar que a modelagem se torna relevante para o estudo de variáveis climáticas e índices de conforto no interior de galpões para confinamento de gado. Resultados semelhantes de benefício da modelagem geoestatística foram observados por Silva et al. (2012). Estes afirmam que o estudo da variabilidade espacial da temperatura do ar e a construção de mapas de krigagem podem auxiliar no manejo correto dos sistemas de climatização em currais de préordenha para bovinos leiteiros. Os autores verificaram também que a construção de mapas possibilitou definir áreas especificas com diferentes variabilidades para a temperatura do ar. 

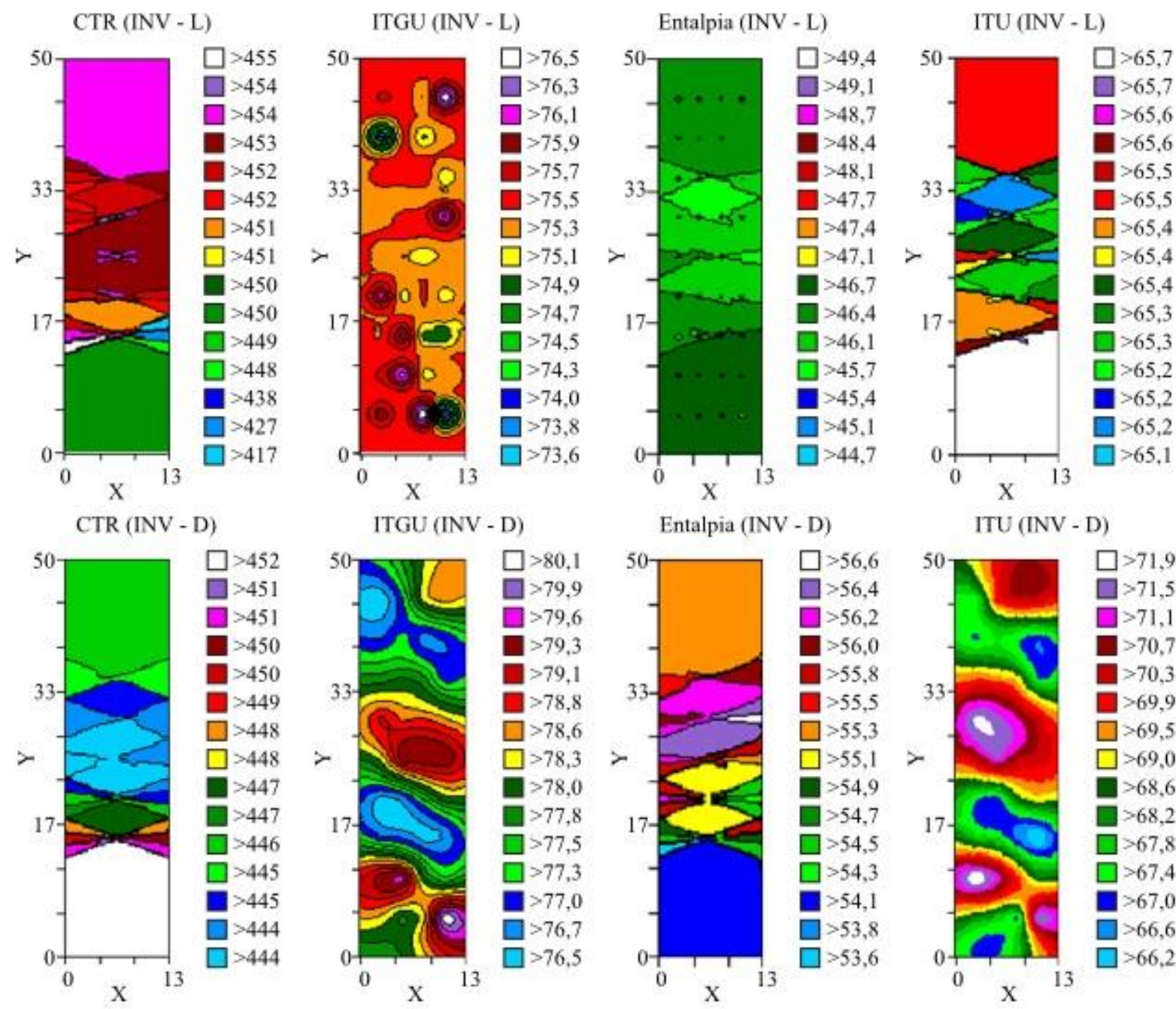

$$
\text { Entalpia (INV - D) }
$$

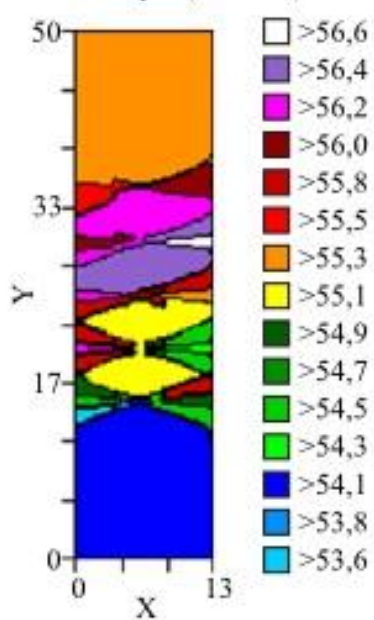

ITU (INV - D)

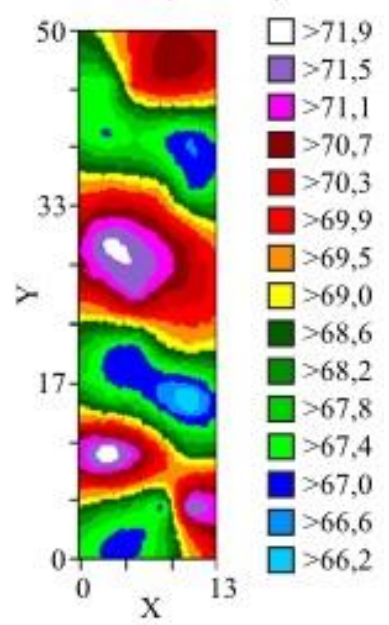

Figura 5. Mapas de krigagem relativos ao índice de Temperatura e Umidade (ITU), índice de temperatura de globo negro e umidade (ITGU), índice de Carga Térmica Radiante (CTR) e a Entalpia, com ventiladores ligados (L) e desligados (D) às 15:00 h no inverno de 2016 .

\section{Conclusão}

Com base nos resultados pode-se concluir que a modelagem geoestatística mostrou-se eficiente para representar e estudar o microclima no interior de um galpão modelo Compost Barn. Com base nos mapas dos índices de Temperatura e Umidade (ITU), Temperatura de Globo Negro e Umidade (ITGU), Carga Térmica Radiante (CTR) e Entalpia (H), estimados por krigagem ordinária, foi possível visualizar melhor a condição do ambiente interno na área de descanso dos animais, tendo-se identificado pontos específicos de desconforto para as vacas leiteiras.

\section{Referências bibliográficas}

Akaike, H. (1974). A new look at the statistical model identification. Automatic Control, IEEE Transactions on Automatic Control, 19(6):716-723.

Araujo, J. I. M., Araujo, A. C., Fonseca, W. J. L., Barros Junior, C. P., Luz, C. S. M., Araujo, J. M., . . . Sousa Júnior, S. C. (2016). Efeitos das variáveis climáticas sobre características fisiológicas de vacas mestiças (Holandês x Gir) em lactação. Revista Acadêmica: Ciência Animal, 14185-193.

Avila, A. S., Jácome, I. M. T. D., Faccenda, A., Panazzolo, D. M. \& Müller, É. R. (2013). Evaluation and correlation of physiological parameters and bioclimatic indexes holstein cows in different seasons. Electronic Journal of Management, Education and Environmental Technology, 14(14):2878-2884. 
Banzatto, D. A. \& Kronka, S. N. (2015). Experimentação Agrícola. Jaboticabal, São Paulo, Brasil: Funep.

Barnabé, J., Pandorfi, H., Almeida, G. L. P., Guiselini, C. \& Jacob, A. L. (2015). Conforto térmico e desempenho de bezerras Girolando alojadas em abrigos individuais com diferentes coberturas. Revista Brasileira de Engenharia Agricola e Ambiental-Agriambi, 19(5):481-488.

Black, R. A., Taraba, J. L., Day, G. B., Damasceno, F. A., Newman, M. C., Akers, K. A., . . Bewley, J. M. (2014). The relationship between compost bedded pack performance, management, and bacterial counts. Journal of Dairy Science, 97(5):2669-2679.

Cambardella, C. A., Moorman, T. B., Parkin, T. B., Karlen, D. L., Novak, J. M., Turco, R. F. \& Konopka, A. E. (1994). Field-scale variability of soil properties in central Iowa soils. Soil Science Society of America Journal, 58(5):1501-1511.

Eckelkamp, E. A., Taraba, J. L., Akers, K. A., Harmon, R. J. \& Bewley, J. M. (2016). Sand bedded freestall and compost bedded pack effects on cow hygiene, locomotion, and mastitis indicators. Livestock Science, 19048-57.

Endres, M. I. \& Barberg, A. E. (2007). Behavior of dairy cows in an alternative bedded-pack housing system. Journal of Dairy Science, 90(9):4192-4200.

Endres, M. I. \& Janni, K. A. (2008). Compost bedded pack barns for dairy cows. University of NebraskaLincoln, 11-9.

Faria, F. F., Moura, D. J., Souza, Z. M. \& Matarazzo, S. V. (2008). Variabilidade espacial do microclima de um galpão utilizado para confinamento de bovinos de leite. Ciência Rural, 38(9):2498-2506.

Ferreira, R. A. (2015). Maior produção com melhor ambiente: Para aves, suínos e bovinos. Viçosa, Minas Gerais, Brasil: Aprenda Fácil.

Gamma Design Software. 2018. GS+: Geostatistics for the Environmental Sciences. Version 10. Gamma Design Software, Plainwell, Michigan USA, http://www.gammadesign.com.

Gonçalves, I., Turco, S. H. N. \& Ramos, C. (2016). Spatial variability of air temperature in a free-stall in the Northeastern semi-arid region of Brazil. Revista Brasileira de Engenharia Agrícola $e$ Ambiental, 20(1):67-71.

Kawabata, C. Y., Castro, R. C. \& Savastano Júnior, H. (2005). Índices de conforto térmico e respostas fisiológicas de bezerros da raça holandesa em bezerreiros individuais com diferentes coberturas. Engenharia Agrícola, 25(3):598-607.

Köppen, W. \& Geiger, R. (1928). Klimate der Erde. Gotha: Verlag Justus Perthes. Wall-map $150 \mathrm{~cm} x 200 \mathrm{~cm}$.

Leso, L., Uberti, M., Morshed, W. \& Barbari, M. (2013). A survey of Italian compost dairy barns. Journal of Agricultural Engineering, 44(3):17.

Medeiros, B. B. L., Moura, D. J., Massari, J. M., Carvalho, T. M. R. \& Maia, A. P. A. (2014). Uso da geoestatística na avaliação de variáveis ambientais em galpão de suínos criados em sistema "wean to finish" na fase de terminação. Engenharia Agrícola, 34(5):800-811.

Mota, V. C., Campos, A. T., Damasceno, F. A., Resende, E. A. M., Rezende, C. P. A., Abreu, L. R. \& Vareiro, T. (2017). Confinamento para bovinos leiteiros: histórico e características. PUBVET, 11(5):433-442.

Mota, V. C., Damasceno, F. A. \& Leite, D. F. (2018). Fuzzy clustering and fuzzy validity measures for knowledge discovery and decision making in agricultural engineering. Computers and Electronics in Agriculture, 150118-124.

Moura, A. K., Mattos Negrão, F., Dantas, C. C. O., Geron, L. J. V., Capovilla, L. C. T. \& Vargas, M. A. (2010). Influências bioclimáticas e de ambiência no bem-estar de vacas leiteiras. PUBVET, 4(32):924-930.

Pilatti, J. A. \& Vieira, F. M. C. (2017). Environment, behavior and welfare aspects of dairy cows reared in compost bedded pack barns system. Journal of Animal Behaviour and Biometeorology, 5(3):97105. 
Queiroz, M. L. V., Barbosa Filho, J. A. D., Sales, F. A. L., Lima, L. R. \& Duarte, L. M. (2017). Variabilidade espacial do ambiente em galpões de frango de corte com sistema de nebulização. Revista Ciência Agronômica, 48(4):586-595.

Silva, I. M., Pandorfi, H., Almeida, G. L. P., Guiselini, C., Caldas, A. M. \& Jacob, A. L. (2012). Análise espacial das condições térmicas do ambiente pré-ordenha de bovinos leiteiros sob regimes de climatização. Revista Brasileira de Engenharia Agrícola e Ambiental, 16(8):903-910.

Webster, R. \& Oliver, M. A. (2001). Geostatistics for Environmental Scientists. United States: John Wiley \& Sons Inc.

Yamamoto, J. K. \& Landim, P. M. B. (2013). Geoestatística: conceitos e aplicações. São Paulo, São Paulo, Brasil: Editora Oficina de Letras.

Recebido: 23 de janeiro, 2019.

Aprovado: 15 de fevereiro, 2019.

Publicado: 27 de fevereiro, 2019.

Licenciamento: Este artigo é publicado na modalidade Acesso Aberto sob a licença Creative Commons Atribuição 4.0 (CC-BY 4.0), a qual permite uso irrestrito, distribuição, reprodução em qualquer meio, desde que o autor e a fonte sejam devidamente creditados 